\title{
Moisture-related changes in the nanostructure of woods studied with X-ray and neutron scattering
}

\author{
Paavo A. Penttilä (i) - Michael Altgen • Nico Carl • Peter van der Linden • \\ Isabelle Morfin • Monika Österberg • Ralf Schweins • Lauri Rautkari
}

Received: 26 June 2019/Accepted: 9 October 2019/Published online: 19 October 2019

(C) The Author(s) 2019

\begin{abstract}
Wood and other cellulosic materials are highly sensitive to changes in moisture content, which affects their use in most applications. We investigated the effects of moisture changes on the nanoscale structure of wood using X-ray and neutron scattering, complemented by dynamic vapor sorption. The studied set of samples included tension wood and normal hardwood as well as representatives of two softwood species. Their nanostructure was characterized in wet state before and after the first drying as well as at relative humidities between 15 and $90 \%$. Small-angle neutron scattering revealed changes on the microfibril level during the first drying of wood samples, and the
\end{abstract}

Electronic supplementary material The online version of this article (https://doi.org/10.1007/s10570-019-02781-7) contains supplementary material, which is available to authorized users.

P. A. Penttilä · M. Altgen · M. Österberg · L. Rautkari Department of Bioproducts and Biosystems, Aalto University, Vuorimiehentie 1, P.O. Box 16300, 00076 Espoo, Finland

P. A. Penttilä $(\bowtie) \cdot$ N. Carl · R. Schweins

Science Division/Large-Scale Structures Group, Institut Laue-Langevin, 71 Avenue des Martyrs, 38042 Grenoble, France

e-mail: paavo.penttila@aalto.fi

P. van der Linden

Partnership for Soft Condensed Matter (PSCM), ESRF The European Synchrotron, 71 Avenue des Martyrs,

38043 Grenoble, France structure was not fully recovered by immersing the samples back in liquid water. Small and wide-angle $\mathrm{X}$-ray scattering measurements from wood samples at various humidity conditions showed moisture-dependent changes in the packing distance and the inner structure of the microfibrils, which were correlated with the actual moisture content of the samples at each condition. In particular, the results implied that the degree of crystalline order in the cellulose microfibrils was higher in the presence of water than in the absence of it. The moisture-related changes observed in the wood nanostructure depended on the type of wood and were discussed in relation to the current knowledge on the plant cell wall structure.

\author{
I. Morfin \\ Laboratoire Interdisciplinaire de Physique (LIPHY), \\ Université Grenoble Alpes, 38000 Grenoble, France \\ I. Morfin \\ LIPHY, CNRS, 38000 Grenoble, France
}




\section{Graphic abstract}

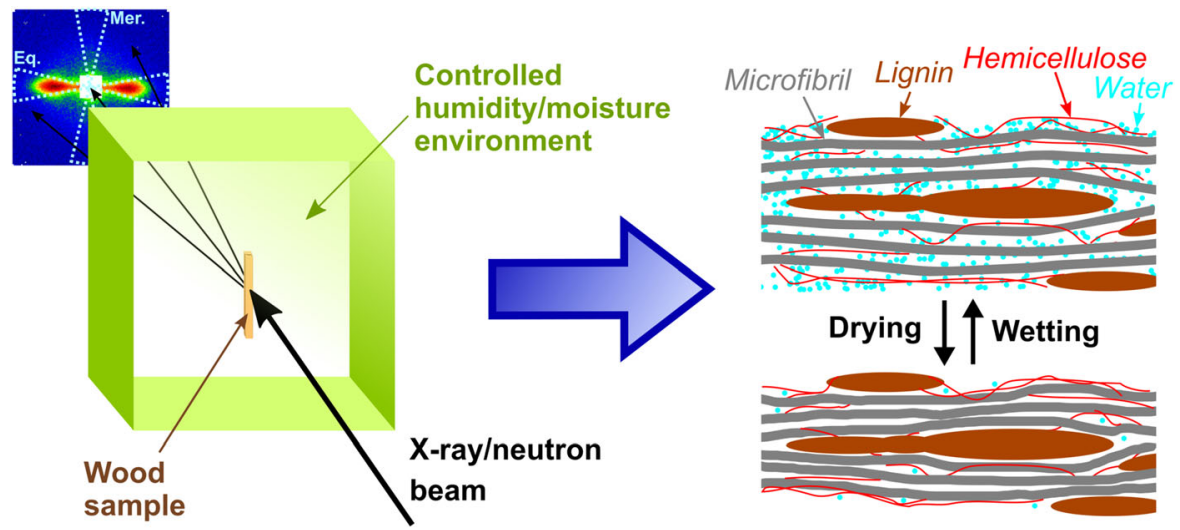

Keywords Wood S Structural characterization · Humidity $\cdot$ Small-angle scattering $\cdot \mathrm{X}$-ray scattering · Sorption

\section{Introduction}

Wood is an extremely abundant, renewable material that has been used in various applications throughout the history of humankind. It has been widely utilized as a construction material, raw-material for paper and, more recently, as a source of cellulose nanofibrils and other nanoscale constituents for advanced materials and applications (Jiang et al. 2018).

It is well known, that moisture content and history are crucial factors determining the properties of wood as a material. For instance, wood becomes stiffer as a consequence of drying, thereby loosing its flexibility and forming cracks, and most of these effects can be traced down to the nanoscale structure of the cell wall (Alméras and Clair 2016; Dinwoodie 2000). From the aspect of utilizing cellulosic fibers and fibrils in pulping or nanocellulose applications, moisture and moisture-induced structural changes are ever more important. The accessibility of cellulosic fibrils and other nanoscale components to water is essential for any physico-chemical or enzymatic treatment taking place in an aqueous environment. Therefore, understanding the interactions between water and the nanostructure of wood is of utmost importance.

Water in wood is considered to be present either as free water mainly in the cell lumina or as bound water inside of the cell wall (Glass and Zelinka 2010). When wood is dried from its native, wet state, the free water evaporates first, followed by the slower removal of the bound water. The situation when the lumina are empty of water but the cell walls are still fully hydrated, is referred to as the fiber saturation point. Below the fiber saturation point, wood exhibits sorption hysteresis (Engelund et al. 2013), meaning that a higher water vapor pressure of the environment, presented by relative humidity $(\mathrm{RH})$, is required to reach the same moisture content by adsorption than desorption at a constant temperature.

The main proportion of water in the thickest $\mathrm{S}_{2^{-}}$ layer of the secondary cell wall of wood (Fig. 1) is bound to hydroxyl groups of hemicelluloses and the surfaces of cellulose microfibrils (CMF) (Engelund et al. 2013). The 2 to 3 -nm-thick CMFs, together with hemicelluloses, are aggregated into bundles, which swell by the adsorption of water (Jarvis 2018). Lignin is also included in the secondary cell wall, where it is closely associated with hemicelluloses and possibly also cellulose, providing a more robust and less watersensitive matrix for the CMFs (Kang et al. 2019). In tension wood, a type of reaction wood present in hardwoods, the secondary cell wall contains an additional layer called G-layer, which is characterized by a low microfibril angle and large CMF crosssection (Müller et al. 2006).

It is clear, that changes in the moisture content of the wood cell wall cause also changes in the interactions and morphology of its nanoscale building blocks. However, studying these effects in situ in the changing environment is a methodological challenge, which 


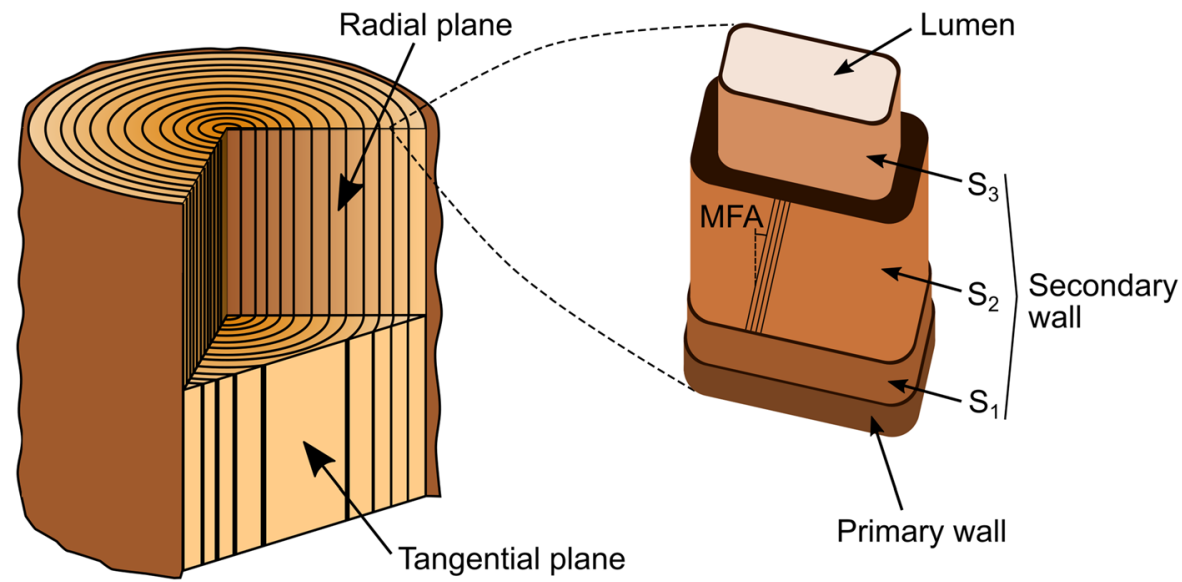

Fig. 1 Simplified model of softwood structure showing the cutting planes and cell wall layering, with the microfibril angle (MFA) illustrated in the $S_{2}$-layer

only few experimental techniques can meet (Rongpipi et al. 2019). Scattering methods applying X-rays and neutrons can be used to obtain averaged nanostructural information from samples under various external conditions, including different moisture contents (Martínez-Sanz et al. 2015). The task is facilitated by a new model developed for analyzing small-angle scattering data from wood (Penttilä et al. 2019).

$\mathrm{X}$-ray and neutron scattering have been widely used to study moisture-induced changes in wood nanostructure. Wide-angle $\mathrm{X}$-ray scattering has shown changes in cellulose crystallites (Abe and Yamamoto 2005; Leppänen et al. 2011; Svedström et al. 2012; Yamamoto et al. 2010; Zabler et al. 2010), whereas the swelling and shrinkage of CMF bundles has been revealed by small-angle scattering of X-rays (Jakob et al. 1996; Leppänen et al. 2011; Penttilä et al. 2019) and neutrons (Fernandes et al. 2011; Penttilä et al. 2019; Plaza et al. 2016; Thomas et al. 2014). In most previous works, however, the changes have been observed during one adsorption or desorption sequence only, and often on only one level of the hierarchical structure. Therefore, a more detailed insight combining experimental results from both structural levels, i.e. the inner structure and packing of $\mathrm{CMFs}$, and correlating them with the actual moisture content is still missing.

The aim of the present work is to describe moistureinduced changes in wood nanostructure, starting from the never-dried state, and relate them to structural parameters obtained from scattering experiments.
Nanoscale structure in different wood samples as a function of moisture conditions was studied using wide-angle X-ray scattering (WAXS) and small-angle $\mathrm{X}$-ray and neutron scattering (SAXS and SANS). The nanostructural changes and the experimentally determined parameters were linked to the actual moisture content of the samples, as measured by a gravimetric technique.

\section{Experimental}

\section{Materials}

Samples from two European beech (Fagus sylvatica) trees, one European silver fir (Abies alba) tree and one Norway spruce (Picea abies) tree were collected in a mountainous area close to Grenoble, France. Small wood blocks cut from the outer part of the xylem were immediately immersed in $\mathrm{H}_{2} \mathrm{O}$ and stored refrigerated. One of the two beech wood samples was later identified as tension wood ("TW"), based on optical microscopy images and the WAXS results. Approximately $1 \times 1 \times 10 \mathrm{~mm}^{3}$ pieces were cut from the samples with a razor blade and either stored as such in liquid water at $7{ }^{\circ} \mathrm{C}$ ("never-dried samples"), conditioned at RH $95 \%$ in a desiccator with saturated $\mathrm{KNO}_{3}$ solution for 9 to 10 days ("preconditioned samples"), or dried first in room air for 2 days, then in a desiccator with silica gel at room temperature (RT) for 3 days, and finally immersed in liquid $\mathrm{H}_{2} \mathrm{O}$ for 5 days ("dried/ 


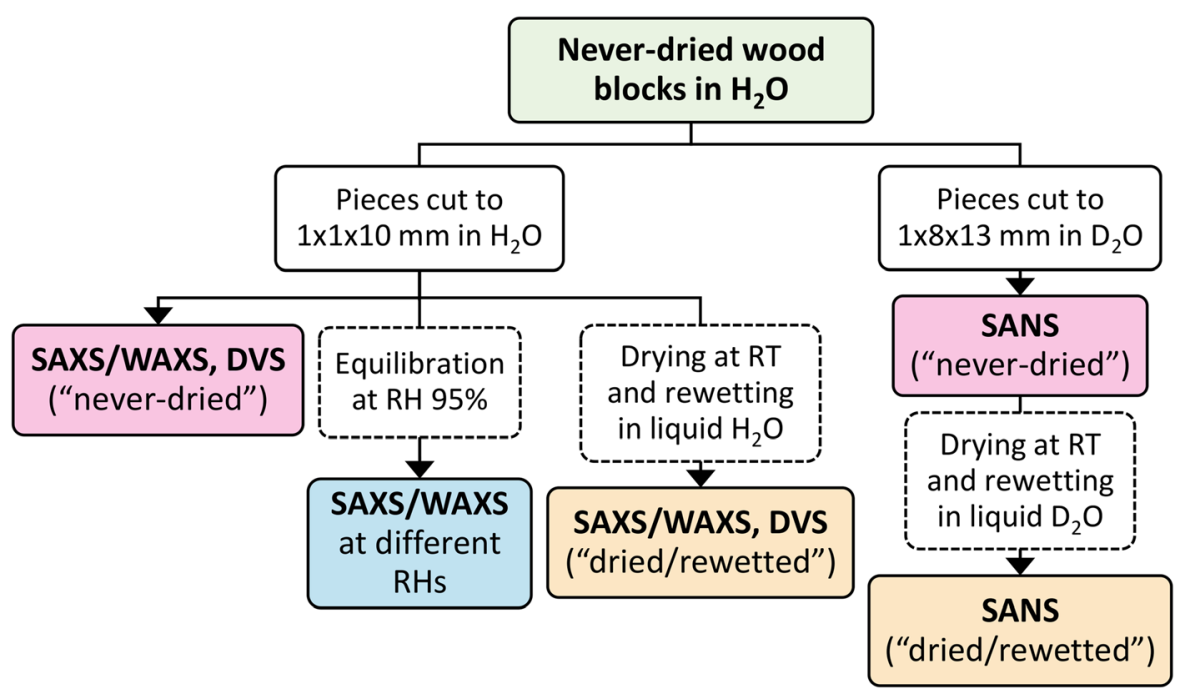

Fig. 2 Chart presenting the different types of samples used for each analysis

rewetted samples"). The samples from fir and spruce contained mostly either earlywood ("EW") or latewood ("LW"), whereas those from beech contained both. In addition, tangential sections from the beech samples and the latewood portions of fir and spruce with approximate dimensions of $1 \times 8 \times 13 \mathrm{~mm}^{3}$ were cut for SANS experiments and the $\mathrm{H}_{2} \mathrm{O}$ was exchanged to $\mathrm{D}_{2} \mathrm{O}$ during a period of several weeks. The drying and rewetting procedures for each analytical method are summarized in Fig. 2.

\section{SANS measurements}

Tangential sections of wood were immersed in liquid $\mathrm{D}_{2} \mathrm{O}$ in quartz cells having a 2-mm optical path, with the longitudinal direction of the wood sections being perpendicular and the radial direction parallel to the neutron beam. SANS was measured at the neutron instrument D11 of Institut Laue-Langevin (ILL), using a neutron wavelength of $6 \AA$ and sample-todetector distances of $1.5 \mathrm{~m}, 8 \mathrm{~m}$ and $34 \mathrm{~m}$. After the first SANS measurements ("never-dried samples"), the samples were dried for 2 days in room air and 12 days in a desiccator, followed by immersion in liquid $\mathrm{D}_{2} \mathrm{O}$ for 5 days. SANS was measured again ("dried/ rewetted samples"), otherwise similarly as for the never-dried samples but with sample-to-detector distances of $1.4 \mathrm{~m}, 8 \mathrm{~m}$ and $39 \mathrm{~m}$. The two-dimensional SANS data was corrected (including subtraction of scattering by empty cell and dark current) and normalized to absolute scale using the Large Array Manipulation Program (LAMP) of the ILL.

\section{SAXS and WAXS measurements}

For the X-ray measurements, the preconditioned samples were placed in a custom-made humidity chamber (Figure S1 of the Electronic Supplementary Material (ESM)) adjusted to RH 90\% and allowed to equilibrate for 4 to $5 \mathrm{~h}$. After measuring the SAXS and WAXS patterns, the RH was changed to $75 \%$ (only for WAXS and low- $q$ SAXS), 45\%, 15\%, 45\%, 75\% (only for WAXS and low- $q$ SAXS) and back to $90 \%$, collecting SAXS and WAXS patterns at each RH point after an equilibration time of 1.5 to $8 \mathrm{~h}$. The neverdried and dried/rewetted samples were measured in the same humidity chamber but without humidity control and in the presence of excess water. The beech samples were placed either with their tangential plane ("TL") or radial plane ("RL") perpendicular to the X-ray beam, whereas all of the softwood samples had their tangential plane perpendicular to the beam. The longitudinal direction of the wood pieces was always vertical and perpendicular to the X-ray beam.

SAXS and WAXS were measured at the D2AM beamline of the European Synchrotron Radiation Facility (ESRF), using an X-ray beam energy of 16 $\mathrm{keV}$ and two setups for the XPAD hybrid-pixel detectors D5 and WOS. In the first setup, the D5 detector was placed at distance $216 \mathrm{~cm}$ from the 
sample to cover the low- $q$ SAXS region (0.006-0.13 $\AA^{-1}$ ) and the WOS detector at distance $13 \mathrm{~cm}$ to measure WAXS $\left(0.61-4.0 \AA^{-1}\right)$. A simultaneous measurement of SAXS and WAXS was enabled by a central hole in the WOS detector. In the second setup, the D5 detector was placed at $58 \mathrm{~cm}$ from the sample in order to cover the high- $q$ SAXS region $\left(0.02-0.49 \AA^{-1}\right)$. In each measurement, the wood samples were scanned horizontally with 7 points within a $1 \mathrm{~mm}$ range, with an exposure time of $40 \mathrm{~s}$ per frame. The $q$-axis was calibrated by measuring a silver behenate sample and the two-dimensional SAXS and WAXS patterns were normalized by the transmitted beam intensity, frame-averaged and corrected for detector efficiency and background contribution from the empty chamber. The frame-averaging was done to minimize the effect of structural heterogeneity and to allow comparison with the SANS data.

Treatment and analysis of scattering data

The treatment and reduction of all SANS, SAXS and WAXS data were carried out as in Penttilä et al. (2019). Briefly, the anisotropic part of the equatorial scattering intensity (perpendicular to the mean fibril axis) was separated from the two-dimensional SANS and SAXS patterns by subtracting the isotropic scattering contribution from intensity integrated on $25^{\circ}$-wide azimuthal sectors. The two-dimensional WAXS data was azimuthally integrated on similar sectors around the equatorial and meridional directions.

The one-dimensional SANS and SAXS intensities representing the anisotropic equatorial scattering were fitted with the WoodSAS model (Penttilä et al. 2019), a model based on infinite cylinders in a hexagonal array with paracrystalline distortion (Hashimoto et al. 1994) and tailored for wood samples:

$$
I(q)=A I_{c y l}(q, \bar{R}, \Delta R, a, \Delta a)+B e^{-q^{2} /\left(2 \sigma^{2}\right)}+C q^{-\alpha}
$$

In Eq. (1), $I_{c y l}(q)$ is the intensity from the cylinder arrays with $\bar{R}$ denoting the mean cylinder radius with standard deviation $\Delta R$ and $a$ the distance between the cylinders' center points with paracrystalline distortion $\Delta a$. The cylinders are assumed to correspond to the CMFs (Penttilä et al. 2019), whereas the third term of the equation, a power-law at low $q$ with exponent $\alpha$ close to 4 , has been assigned to the cell lumina (Jakob et al. 1996; Nishiyama et al. 2014). The second term, a Gaussian function centered at $q=0 \AA^{-1}$, approximates the form factor of other unspecified nanoscale features such as pores (Penttilä et al. 2019).

The fitting of Eq. (1) to SANS and SAXS data was done using the SasView 4.2.0 software (Doucet et al. 2018) and the WoodSAS model plugin (Penttilä et al. 2019), freely-available at the SasView Marketplace (http://marketplace.sasview.org/). In the SANS fits, $\alpha$ was fixed to 4 and $\Delta R / \bar{R}$ to 0.2 . In the SAXS fits, $\alpha$ was fixed to $4, \Delta a / a$ to 0.4 , and $\Delta R / \bar{R}$ to about 0.2 . The fixing of these parameters was done to accelerate the fitting and to reduce the risk of unrealistic fitting results. The values of the fixed parameters were chosen based on both current and previous data (Penttilä et al. 2019). A $q$-independent, constant background was included in the SAXS fits, if necessary.

WAXS data was used to estimate the size of the well-ordered domains (crystal size) by calculating the coherence length $L_{h k l}$ using the Scherrer equation:

$L_{h k l}=\frac{2 \pi}{\Delta q_{h k l}}$,

where $\Delta q_{h k l}$ is the integral breadth of the diffraction peak corresponding to reflection $h \mathrm{kl}$. In doing this, peak broadening due to instrument resolution, which would effectively decrease the coherence length calculated with Eq. (2), was assumed negligible. The integral breadth and peak position $\left(q_{h k l}\right)$ of reflections $h k l=200$ and 004, according to the monoclinic unit cell of cellulose $I_{\beta}$ (Nishiyama et al. 2002), were obtained by peak fitting from equatorial and meridional WAXS intensities, respectively. The equatorial intensities between $q=0.65$ and $2.25 \AA^{-1}$ were fitted with three Gaussian peaks for crystalline cellulose

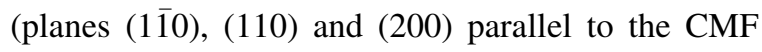
axis), one Gaussian peak for less-ordered cell wall polymers and water (centered around $q=2.0 \AA^{-1}$ in the never-dried and dried/rewetted samples and around $q=1.4 \AA^{-1}$ in other samples) and a constant background. The meridional intensities between $q=$ 2.3 and $2.7 \AA^{-1}$ were fitted with two Gaussian peaks, one of which corresponded to the 004 reflection (plane perpendicular to the CMF axis) and one to the contribution of other nearby reflections, plus a linear 
background. The distances $d_{h k l}$ between parallel lattice planes were obtained as $d_{h k l}=2 \pi / q_{h k l}$. Fitting to WAXS data was done using Python scripts and representative example fits are shown in Figure S2 of the ESM. The fitting to the $1 \overline{1} 0$ and 110 diffraction peaks was prone to errors in both peak position and width, so that the data corresponding to these two peaks was not analyzed further.

\section{Vapor sorption measurements}

Never-dried and dried/rewetted samples with approximate dimensions of $1 \times 1 \times 10 \mathrm{~mm}^{3}$, similar to those used in the SAXS and WAXS experiments, were conditioned over saturated $\mathrm{KNO}_{3}$ solution for 10 days and placed in the dynamic vapor sorption (DVS) apparatus (DVS ET, Surface Measurement Systems, United Kingdom), pre-adjusted to a target RH of $90 \%$. During the entire DVS sequence, the gas flow was kept at $200 \mathrm{~cm}^{3} \mathrm{~min}^{-1}$ using nitrogen. The target RH in the DVS was varied from 90 to $15 \%$ and back with similar steps and durations as during the SAXS experiments at the shorter sample-to-detector distance, as shown in Figure S3 of the ESM. The measured RH values were 1-2 percentage units lower than the target RH (as seen in the figures and tables showing the results). The temperature was kept constant at about $20^{\circ} \mathrm{C}$ during the RH sequence. The dry mass was obtained after the $\mathrm{RH}$ cycle by drying the sample at $60^{\circ} \mathrm{C}$ for $6 \mathrm{~h}$ using the pre-heater of the DVS apparatus, which was followed by a temperature stabilization at about $20^{\circ} \mathrm{C}$ for $2 \mathrm{~h}$. The dry mass after temperature stabilization was used to calculate the moisture content, defined as the mass ratio of adsorbed water and the dry sample, as an average over a 10-min period at the end of each $\mathrm{RH}$ step. After the measurements, the mass stability at the end of each RH step was estimated by the change in mass over time $(d m / d t)$. The $d m / d t$, calculated based on a $1 \mathrm{~h}$ regression window and using the dry mass as the reference mass, was below $20 \mu \mathrm{g} \mathrm{g}^{-1} \min ^{-1}$ at most measurement points, as shown in the ESM (Table S1).

\section{Results and discussion}

Vapor sorption results

DVS was used to determine the moisture content of never-dried and dried/rewetted wood samples below the fiber saturation point, namely at $\mathrm{RH}$ points from approximately 90 to $15 \%$ and back. The results are summarized in Table 1 and the data for never-dried and dried/rewetted beech has been illustrated in the form of a sorption isotherm in Fig. 3. The sorption isotherms of the other samples are presented in the ESM (Figure S4). The shape of the sorption isotherms (Figs. 3 and S4) follow those found in literature (Glass and Zelinka 2010; Engelund et al. 2013), showing

Table 1 Moisture content of wood samples measured with DVS at different RHs during subsequent desorption and adsorption isotherms (columns from left to right), with error estimates based on standard deviation from two or more specimens

\begin{tabular}{|c|c|c|c|c|c|c|}
\hline \multirow[t]{2}{*}{ Sample } & \multirow[t]{2}{*}{ Drying state } & \multicolumn{5}{|c|}{ Moisture content (\%) at different RHs (\%) } \\
\hline & & $88.7 \pm 0.3$ & $43.5 \pm 0.1$ & $12.57 \pm 0.03$ & $43.05 \pm 0.06$ & $88.4 \pm 0.2$ \\
\hline \multirow[t]{2}{*}{ Beech } & Never-dried & $38.6 \pm 0.8$ & $10.74 \pm 0.06$ & $4.51 \pm 0.03$ & $8.80 \pm 0.03$ & $21.5 \pm 0.1$ \\
\hline & Dried/rewetted & $36.1 \pm 0.88$ & $10.73 \pm 0.03$ & $4.51 \pm 0.01$ & $8.82 \pm 0.01$ & $21.41 \pm 0.05$ \\
\hline \multirow[t]{2}{*}{ Beech TW } & Never-dried & $36.5 \pm 0.8$ & $11.0 \pm 0.1$ & $4.90 \pm 0.05$ & $9.14 \pm 0.07$ & $22.4 \pm 0.2$ \\
\hline & Dried/rewetted & $32.5 \pm 0.2$ & $10.97 \pm 0.03$ & $4.87 \pm 0.01$ & $9.14 \pm 0.09$ & $22.2 \pm 0.2$ \\
\hline \multirow[t]{2}{*}{ Fir EW } & Never-dried & 28.0 & 11.9 & 5.4 & 10.1 & 23.4 \\
\hline & Dried/rewetted & 28.2 & 12.0 & 5.4 & 10.2 & 24.1 \\
\hline \multirow[t]{2}{*}{ Fir LW } & Never-dried & $27.6 \pm 0.4$ & $11.44 \pm 0.02$ & $5.26 \pm 0.01$ & $9.66 \pm 0.01$ & $22.5 \pm 0.2$ \\
\hline & Dried/rewetted & 26.8 & 11.3 & 5.2 & 9.6 & 22.4 \\
\hline \multirow[t]{2}{*}{ Spruce EW } & Never-dried & $28.7 \pm 0.4$ & $12.3 \pm 0.2$ & $5.6 \pm 0.1$ & $10.5 \pm 0.1$ & $24.70 \pm 0.05$ \\
\hline & Dried/rewetted & 27.8 & 11.9 & 5.4 & 10.2 & 24.0 \\
\hline \multirow[t]{2}{*}{ Spruce LW } & Never-dried & 28.4 & 11.8 & 5.5 & 10.1 & 23.6 \\
\hline & Dried/rewetted & 26.9 & 11.7 & 5.4 & 9.9 & 23.0 \\
\hline
\end{tabular}




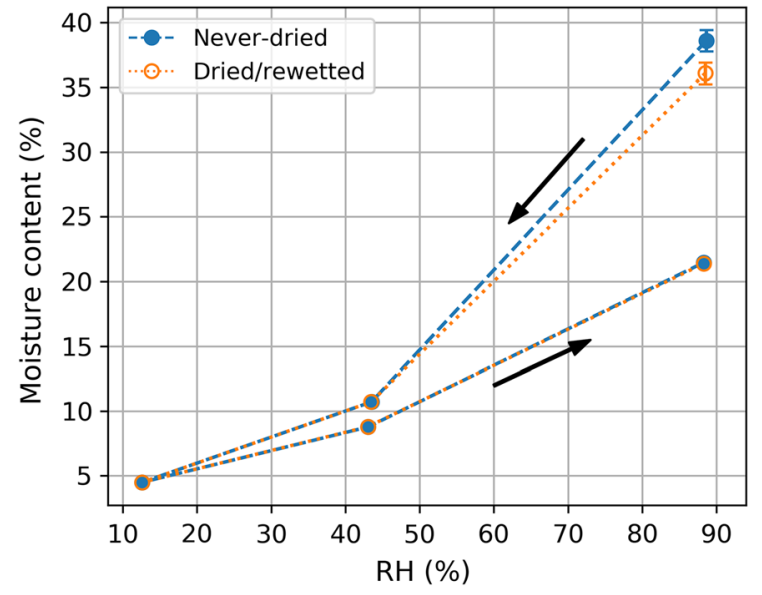

Fig. 3 Example sorption isotherms for beech samples, with the sequence of the data points indicated by arrows

hysteresis as consistently higher moisture content values during a desorption from the never-dried or dried/rewetted state than during a subsequentially measured adsorption isotherm (as seen also in Table 1). Particularly, the moisture content values for all beech wood samples at RH $90 \%$ before and after the RH cycle were in ranges $32-40 \%$ and $21-23 \%$, respectively, indicating a considerable hysteresis effect during a drying cycle from the fully hydrated state. Similarly, the moisture content values for the fir and spruce samples were larger before (27-30\%) than after (22-25\%) the RH cycle, even though the change was less drastic than in the case of beech wood. The originally higher moisture content of the beech wood samples at the start of the RH cycle might be explained by their higher density as compared to the softwoods (Glass and Zelinka 2010), which could also lead to slower equilibration (as indicated by larger $d m / d t$ for the beech samples at the beginning of the RH cycle in Table S1).

Furthermore, the moisture content of never-dried beech was slightly higher than that of the corresponding tension wood at the first measurement point (Table 1), whereas this trend was reversed in all subsequent measurement points. The latter part is in line with other results showing that moisture content in tension wood may be higher than in normal wood (Vilkovská et al. 2018). In the softwood samples, the latewood sections showed generally lower moisture contents than the EW sections (Table 1). A similar result was reported before by Hill et al. (2015) for mature Japanese larch, but the exact reason remained unclear. Differences between the two softwood species were small but consistent, showing slightly higher moisture contents in the spruce samples as compared to the fir samples.

An effect caused by drying and rewetting before the DVS measurement was obvious at the beginning of the RH cycle (RH 90\%), where most of the dried/rewetted samples showed smaller moisture content values than their never-dried counterparts (Table 1). The difference was particularly large in beech tension wood and the spruce samples, whereas only the fir earlywood samples did not show such effect. According to literature (Glass and Zelinka 2010), the first desorption isotherm of never-dried wood is usually above any subsequent desorption isotherm especially at high RHs, even though this behavior may depend on the drying and rewetting procedures (Thybring et al. 2017). In most of the beech and fir samples, the moisture content difference between never-dried and dried/rewetted samples disappeared at later points of the RH cycle, indicating that the effects of drying and rewetting before the DVS measurement were cancelled by reducing the RH to a value between 45 and 90\%. This range coincides with the $\mathrm{RH}$ range where the glass transition of the hemicelluloses is assumed to take place (Engelund et al. 2013). Only the dried and rewetted spruce samples possibly had smaller moisture contents than their never-dried counterparts throughout the RH cycle. All in all, the current DVS data indicate some changes in the water sorption capacity of wood samples dried at RT and rewetted in liquid water as compared to never-dried samples.

\section{SANS results}

SANS was used to compare the aggregation state and cross-sectional diameter of the CMFs between the never-dried and dried/rewetted states. The equatorial, anisotropic SANS intensities (Fig. 4) were fitted with a model based on hexagonally packed cylinders (Penttilä et al. 2019), in order to obtain the mean diameter of the CMFs $(2 \bar{R})$, the distance between the center points of their lateral cross-sections $(a)$ and a parameter describing the relative variation of distance $a(\Delta a / a)$. These parameters are shown in Table 2, whereas the rest of the fitting parameters and plots 


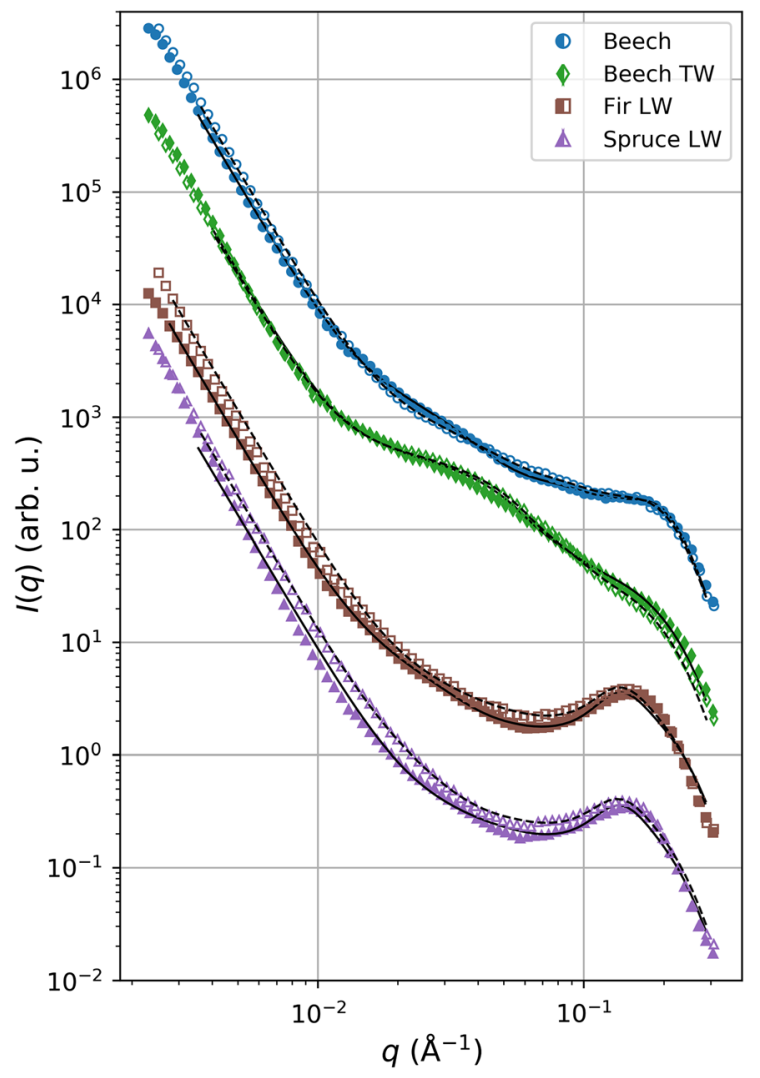

Fig. 4 Equatorial, anisotropic SANS intensities from neverdried (filled symbols) and dried/rewetted (unfilled symbols) wood samples together with fits of Eq. (1) (solid lines for neverdried, dashed lines for dried/rewetted), shifted vertically for clarity

showing the different terms of the fitting function are included in the ESM (Table S2 and Figure S5).

The results of the SANS fits (Table 2) showed similar values as determined previously with the same methodology for both softwoods and normal hardwoods in wet state (Fernandes et al. 2011; Penttilä et al. 2019; Plaza et al. 2016; Thomas et al. 2014). The CMF diameter $(2 \bar{R})$ was around $2 \mathrm{~nm}$ in all samples and their packing distance (a) 4.3-4.4 nm in both softwoods and close to $3 \mathrm{~nm}$ in beech normal wood. The tension wood samples of beech, on the other hand, produced a different shape of the SANS intensity curve, with a strong contribution at $q$ values from 0.01 to $0.1 \AA^{-1}$ (Fig. 4). Fits to these samples yielded a considerably larger value for the interfibrillar distance (above $6 \mathrm{~nm}$ ) as compared to normal wood (Table 2), and a significantly higher contribution of the Gaussian term (term with $B$ in Eq. (1)) was required to model the scattering on the $q$ range from 0.01 to $0.1 \AA^{-1}$ (Table S2 and Figure S5). The peculiar shape of the SANS intensity curve of beech tension wood is similar to those reported for poplar tension wood by Sawada et al. (2018), who assigned the additional contribution to associated CMFs and mesopores (diameter $6 \mathrm{~nm}$ ), and it is therefore suggested to be characteristic of tension wood samples.

The SANS results showed small but rather consistent differences between never-dried and dried/rewetted structures of the samples (Table 2). The CMF diameter $(2 \bar{R})$ of dried/rewetted beech tension wood and fir latewood was $4 \%$ larger than in the never-dried state, with the other samples showing almost no difference. At the same time, the interfibrillar distance (a) was 2-3\% smaller after drying and rewetting in all the normal wood samples, with slightly increased polydispersity parameter $\Delta a / a$. Also the power-law scattering at low $q$ values in the normal wood samples was stronger after drying and rewetting (parameter

Table 2 Results of fits to SANS data from never-dried and dried/rewetted woods, with $2 \bar{R}$ being the mean CMF diameter, $a$ the CMF packing distance and $\Delta a / a$ the polydispersity of $a$

\begin{tabular}{lllcc}
\hline Sample & Drying state & $2 \bar{R}(\mathrm{~nm})$ & $a(\mathrm{~nm})$ & $\Delta a / a$ \\
\hline Beech & Never-dried & $2.09 \pm 0.01$ & $2.74 \pm 0.01$ & $0.371 \pm 0.004$ \\
& Dried/rewetted & $2.08 \pm 0.02$ & $2.67 \pm 0.02$ & $0.411 \pm 0.005$ \\
Beech TW & Never-dried & $2.00 \pm 0.02$ & $6.44 \pm 0.05$ & $0.38 \pm 0.01$ \\
& Dried/rewetted & $2.08 \pm 0.01$ & $6.54 \pm 0.04$ & $0.344 \pm 0.008$ \\
Fir LW & Never-dried & $1.91 \pm 0.09$ & $4.4 \pm 0.1$ & $0.30 \pm 0.01$ \\
& Dried/rewetted & $1.99 \pm 0.08$ & $4.3 \pm 0.1$ & $0.31 \pm 0.01$ \\
Spruce LW & Never-dried & $2.05 \pm 0.01$ & $4.37 \pm 0.01$ & $0.307 \pm 0.001$ \\
& Dried/rewetted & $2.06 \pm 0.01$ & $4.29 \pm 0.02$ & $0.326 \pm 0.002$ \\
\hline
\end{tabular}

The error margins correspond to the errors of fitting provided by the fitting software 
$C$ in Table S2). On the other hand, opposite trends were observed in the tension wood samples of beech, where the interfibrillar distance increased by about $2 \%$ and the power-law scattering slightly weakened as a consequence of drying and rewetting. These results suggest that the drying-induced changes in the wood nanostructure, particularly in the cross-sectional diameter and packing distance of CMFs, were specific to the type of wood and were not fully recovered by immersing the samples back in liquid water for several days.

\section{SAXS results}

To observe the effects of gradual humidity and moisture changes on the lateral dimensions and packing of the CMFs, SAXS measurements of the wood samples were conducted under controlled humidity conditions as well as from never-dried and dried/rewetted samples saturated with liquid water. In the experiments at different humidities, the $\mathrm{RH}$ of the sample environment was varied from 90 to $15 \%$ (samples denoted "(d)" for down) and back ("(u)" for up), and SAXS measurements were done at each extreme and at RH 45\%. The equatorial, anisotropic SAXS intensities from beech, TL at different moisture conditions, together with fits of Eq. (1), are shown as an example in Fig. 5 and the data from the other samples is included in the ESM (Figure S6). The results of the most important fitting parameters are summarized in Fig. 6 and the rest are given in the ESM (Table S3).

Although individual samples and humidity points show some unsystematic deviations, attributed for instance to lower contrast between the CMFs and the surrounding matrix at low moisture contents, a number of trends can be found from the fitting results (Fig. 6). The contribution of the cylinder term $(A)$ was highest in the wet state and became smaller at low RHs, with the value at $\mathrm{RH} 90 \%$ before the drying being larger than after drying in all samples. The CMF diameter $2 \bar{R}$ generally decreased at low RHs, even though the change especially in beech normal wood was very modest. The distance $a$ in beech tension wood and the softwood samples decreased at low RHs, whereas almost no change was seen in the normal wood samples of beech. The scaling factor of the Gaussian term $(B)$ increased at low RHs in the softwood

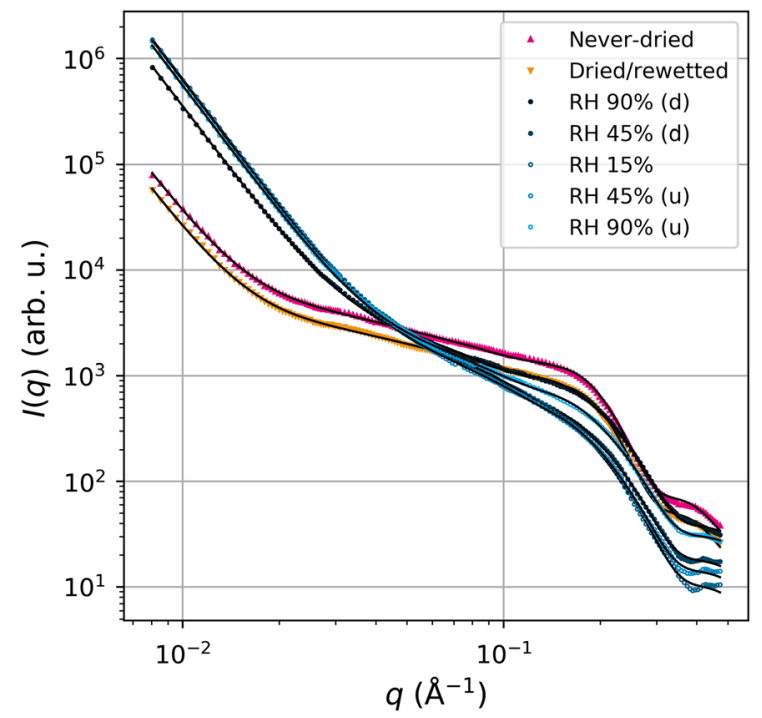

Fig. 5 Examples of equatorial, anisotropic SAXS intensities from beech, TL at various moisture conditions (dots) and fits of Eq. (1) (solid lines), with “(d)" and "(u)" in the legend referring to the change of RH down and up, respectively

samples, decreased in beech tension wood, and remained about the same in beech normal wood. The scaling factor of the power-law scattering from surfaces of larger pores $(C)$ increased at low RHs, especially compared to the water-saturated states. As a whole, the changes of the fitting parameters with moisture content followed the trends reported previously based on SAXS experiments during drying (Penttilä et al. 2019). Some of the changes were obvious also in the plotted SAXS intensities (Figs. 5 and S6), such as the gradual weakening and shift of the shoulder feature from the CMFs (close to $q=0.2 \AA^{-1}$ ) to higher $q$ values and the strong increase of the low- $q$ power-law scattering with decreasing moisture content.

In comparison with the SANS results ("SANS results" section), the values of $2 \bar{R}$ and $a$ determined with SAXS for never-dried and dried/rewetted samples were of similar magnitude. Moreover, the SAXS data of beech tension wood reproduced a similarly strong scattering between $q=0.01$ and $0.1 \AA^{-1}$ as observed with SANS, and it was reflected in the larger value of $B$ as compared to the normal wood samples (Fig. 6 and Table S3). However, contrary to the trends observed with SANS, the distance $a$ determined with SAXS actually increased by $2-5 \%$ in the softwood samples as a consequence of drying and rewetting. The 


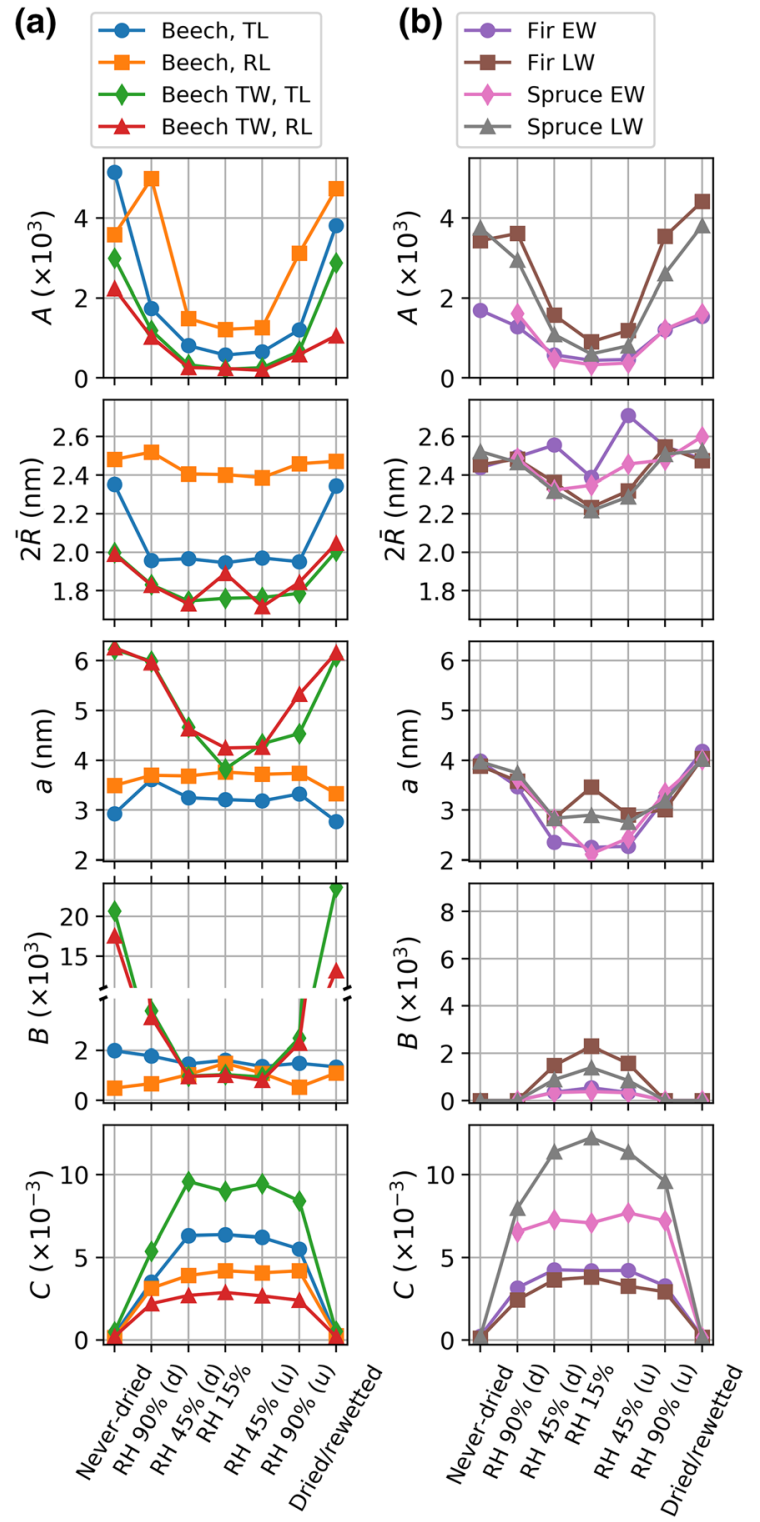

Fig. 6 SAXS results showing the variation of the scaling factor of the cylinder arrays $(A)$, CMF diameter $(2 \bar{R})$, interfibrillar distance $(a)$, and the scaling factors of the Gaussian term $(B)$ and power-law scattering $(C)$ according to Eq. (1), as a function of humidity conditions: a Beech normal wood and tension wood, b Fir and spruce

contradictory result between the two methods might be related to the poorer resolvability of the interfibrillar correlation peak in SAXS than SANS data, making the SANS result appear more reliable. No clear differences were detected between parameters obtained for the two softwood species or their earlywood and latewood sections, which is in line with previous SAXS results (Jakob et al. 1994; Suzuki and Kamiyama 2004). Only the moisture behavior of the two earlywood samples was possibly more similar to each other than to that of the latewood samples.

Besides the lateral structure of the CMFs and bundles thereof, SAXS can also be used to detect their orientation and, most concretely, the microfibril angle (Lichtenegger et al. 1999). In order to roughly illustrate any moisture-dependent changes in the orientation of the fibrils, the azimuthal full width at half maximum (FWHM) of the equatorial intensity streak, obtained during the initial treatment of the twodimensional SAXS data ("Treatment and analysis of scattering data" section), was averaged over two $q$ ranges at each moisture condition (Figure S7 in the ESM). The azimuthal FWHM corresponding to the length scale of individual CMFs and their bundles (3-30 nm, Figure S7a) increased for beech tension wood at low RHs, whereas no significant variation with moisture was observed in the other samples. In the scale of the individual CMFs (1-3 nm, Figure S7b), the azimuthal FWHM increased in the beech tension wood samples as well as in the TL section of beech normal wood and possibly also in spruce earlywood. At the same time, some of the other softwood samples showed indications of a decreased width at low RHs. Interpreting moisture-dependent changes based on the azimuthal distribution of SAXS intensity from wood samples is rather difficult, because equatorial scattering may arise also from other features than CMFs and their bundles. In particular, the scattering contribution dominating the equatorial intensity between $q=0.01$ and $0.1 \AA^{-1}$, modeled mostly by the term with $B$ in Eq. (1), could arise from nanoscale pores between the CMFs and CMF bundles. Nevertheless, these qualitative observations on moisture-dependent changes of the azimuthal intensity distribution might be of help when interpreting changes in other nanoscale structural parameters.

\section{WAXS results}

For understanding moisture-related changes in the inner structure of the CMFs, WAXS data from the wood samples at different moisture conditions were measured simultaneously with the SAXS data of the longer sample-to-detector distance. The WAXS 


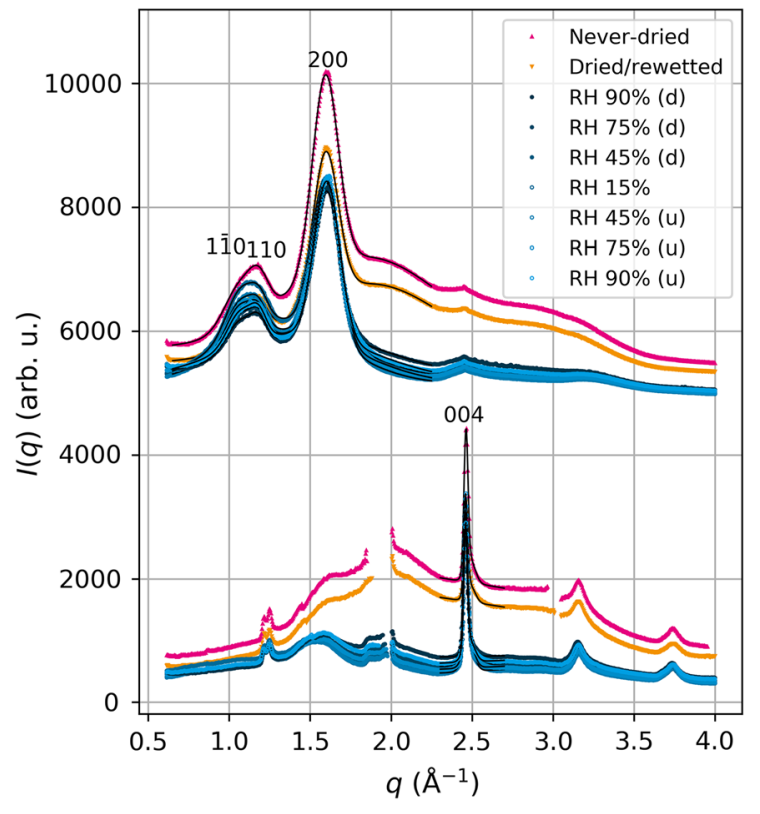

Fig. 7 Examples of equatorial (above, vertically shifted) and meridional (below) WAXS intensities from beech, TL at various moisture conditions and fits used to determine the coherence length $L_{h k l}$ and lattice spacings $d_{h k l}$ (solid lines)

intensities integrated on equatorial and meridional sectors of the two-dimensional detector, together with fits of Gaussian peaks as described in "Treatment and analysis of scattering data" section, are presented for beech, TL in Fig. 7 and for the rest of the samples in Figure S8 in the ESM. The discontinuities in the meridional intensities are due to gaps between the detector modules. The lattice spacings $d_{h k l}$ and coherence lengths $L_{h k l}$, as calculated from these fits for the directions perpendicular $(h k l=200)$ and parallel $(h k l=004)$ to the CMF axis, are shown in Fig. 8.

The lattice spacings $d_{200}$ and $d_{004}$ (Fig. 8) were of a typical magnitude and followed the general trends observed before in drying wood samples (Abe and Yamamoto 2005; Leppänen et al. 2011; Zabler et al. 2010; Yamamoto et al. 2010; Svedström et al. 2012): the lattice spacing perpendicular to the CMF axis $\left(d_{200}\right)$ increased at low RHs, whereas that parallel to the CMF axis $\left(d_{004}\right)$ decreased. These changes can be explained by drying deformations caused by the shrinking hemicellulose matrix around the CMFs, which at the same time pulls apart the CMFs in their lateral direction and contracts them in the longitudinal direction (Abe and Yamamoto 2005; Yamamoto et al. 2010; Leppänen et al. 2011). Only some of the values

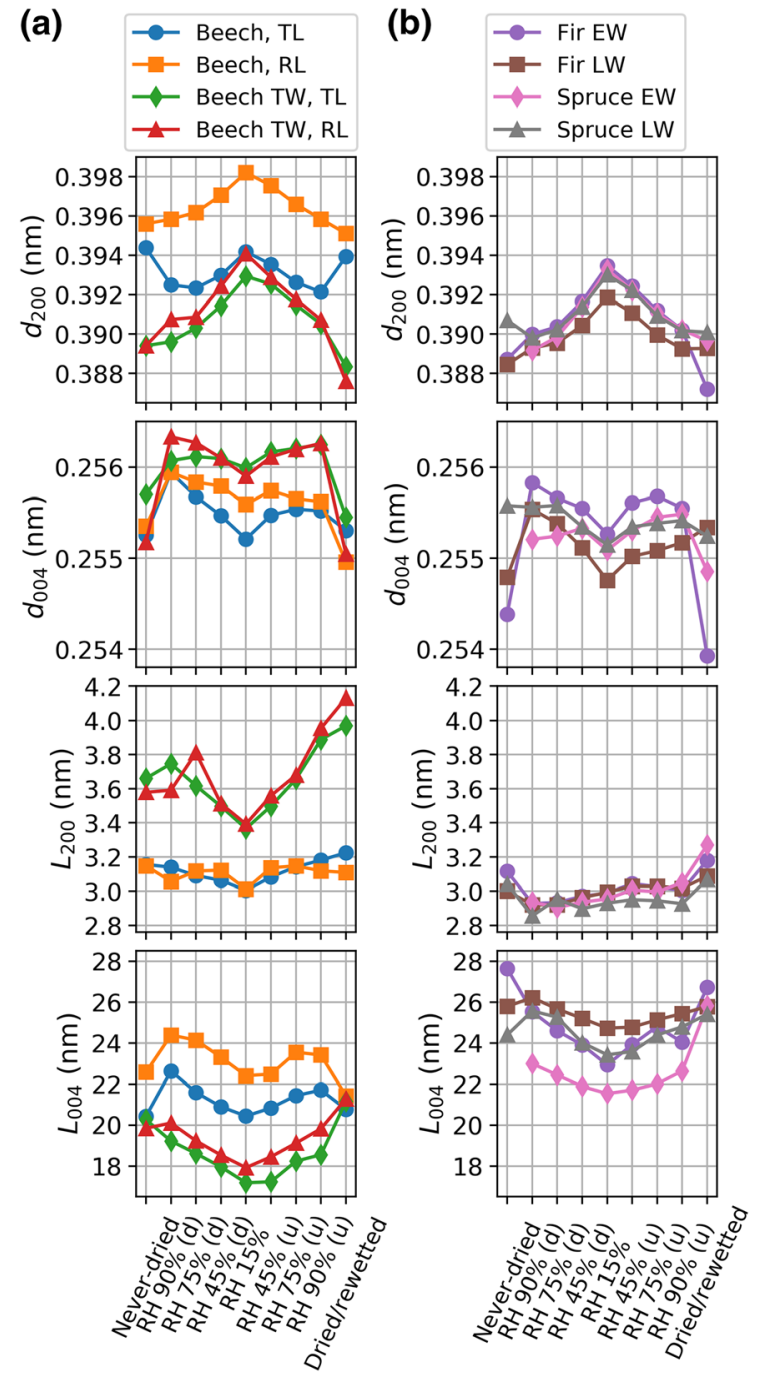

Fig. 8 WAXS results showing the variation of the lattice spacing $\left(d_{h k l}\right)$ and coherence length $\left(L_{h k l}\right)$ for $h k l=200$ and 004 as a function of humidity conditions: a Beech normal wood and tension wood, b Fir and spruce

in the fully-hydrated states, especially those of $d_{004}$, behaved in an unsystematic way, which in principle could be caused by the disturbing effect of the strong water background on the peak fitting. The percentual changes of the lattice spacings (around $1 \%$ for $d_{200}$ and of the order of $0.1 \%$ for $d_{004}$ ) were similar to those obtained by others (Leppänen et al. 2011; Svedström et al. 2012; Yamamoto et al. 2010; Zabler et al. 2010) and they were mostly reversible, as also reported by Zabler et al. (2010). As a special feature of beech tension wood, its $d_{200}$ was slightly smaller and $d_{004}$ 
larger than those of the corresponding normal wood, the first observation being in accordance with the results of Yamamoto et al. (2010).

The values of the coherence length $\left(L_{200}\right.$ and $L_{004}$, Fig. 8) were also in agreement with previous results for similar wood samples (Andersson et al. 2004; Leppänen et al. 2011; Penttilä et al. 2013, 2019), including the larger $L_{200}$ 's of tension wood as compared to normal wood (Müller et al. 2006). The moisture behavior of the lateral coherence length $L_{200}$ varied between different types of wood samples. In the beech samples, $L_{200}$ decreased with desorption and increased with adsorption, more strongly in tension wood than in normal wood, whereas all the softwood samples showed higher values at the fully-hydrated states and an almost continuous increase of $L_{200}$ during the RH cycle from 90 to $15 \%$ and back. The parameter $L_{200}$ seemed also larger in the dried/rewetted state as compared to the original, never-dried state, at least in the softwood and beech tension wood samples, which is in line with the changes of the CMF diameter observed with SANS in "SANS results" section. Previously, a decrease of $L_{200}$ as a consequence of drying has been reported for both softwoods (Svedström et al. 2012; Toba et al. 2013) and hardwoods (Leppänen et al. 2011; Yamamoto et al. 2010), with a stronger effect seen in tension wood than in normal wood, as well as for cotton fibers (Fang and Catchmark 2014). A growth of the $L_{200}$ coherence length with repeated drying and wetting treatments has been observed before at least in two Japanese softwoods (Toba et al. 2013). An explanation for the larger $L_{200}$ in the wet state could be possibly found in the drying-induced stresses, which in addition to increasing the lattice spacing $d_{200}$, would also disturb the order of the cellulose chains on CMF surfaces or cause some other kind of deformations in the crystal structure (Fang and Catchmark 2014; Toba et al. 2013; Yamamoto et al. 2010).

Interestingly, changes in $\mathrm{RH}$ affected the parameter $L_{004}$ in a systematic way, producing smaller values at low RHs for all samples. Only some of the never-dried and dried/rewetted samples deviated from this trend, which could be again caused by the involvement of the strong water background in the fits. The changes in the coherence length $L_{004}$ were similar to the results of Leppänen et al. (2011) and Svedström et al. (2012), who reported increases of up to $20 \%$ for the 004 peak width in both hardwood and softwood samples during drying. These results can be interpreted as a longer axial coherence length of the crystals in the presence of more moisture. Therefore, the changes in both diffraction peaks (200 and 004) imply that the cellulose chains in the CMFs have a higher degree of order in the presence of water than in the absence of it, which is a conclusion previously made based on Raman spectra (Agarwal 2014).

The orientational distribution of cellulose crystallites was analyzed by determining the azimuthal width of the 200 reflection of cellulose $\mathrm{I}_{\beta}$ by a Gaussian fit (Figure S9 in the ESM). The azimuthal FWHM (Figure S10) was clearly largest in spruce (mostly around $30^{\circ}-40^{\circ}$ ), whereas values between $15^{\circ}$ and $23^{\circ}$ were obtained for the other samples. The azimuthal FWHM values for beech tension wood were smaller than for the corresponding normal wood, as expected based on the generally smaller microfibril angle of tension wood (Donaldson 2008). Interestingly, the azimuthal FWHM values determined from the 200 reflection for all samples were somewhat smaller than those obtained from the SAXS intensities representing the length scale of the CMF cross-section (from $20^{\circ}$ to $65^{\circ}$, Figure S7). This difference is partly explained by the contribution of non-cellulosic structures such as oriented nanopores to the SAXS intensities, but might also be related to a more uniform orientation of larger crystallites that dominate the WAXS intensities. Roughly similar changes with moisture conditions were seen as in the case of the SAXS intensities ("SAXS results" section): the disorientation increased at low RHs in beech tension wood, and possibly also the spruce samples were affected, whereas the changes in the other samples were negligible. These results are in line with the reported small increase of the microfibril angle in tension wood samples with drying (Leppänen et al. 2011).

Correlations between moisture content and nanostructural parameters of wood below fiber saturation point

In order to remove the effect of sorption hysteresis prior to further discussion, the nanostructural parameters determined from the scattering experiments at different moisture conditions should be linked to the actual moisture content of the samples. For this 
Table 3 Percentage change of nanostructural parameters per percentage unit of moisture content, determined using SAXS and WAXS between $\mathrm{RH}$ values $15 \%$ and $90 \%$

\begin{tabular}{|c|c|c|c|c|c|c|}
\hline \multirow[t]{2}{*}{ Sample } & \multicolumn{2}{|l|}{ SAXS } & \multicolumn{4}{|l|}{ WAXS } \\
\hline & $2 \bar{R}$ & $a$ & $d_{200}$ & $d_{004}$ & $L_{200}$ & $L_{004}$ \\
\hline Beech, TL & $0.00 \pm 0.04$ & $0.4 \pm 0.1$ & $-0.01 \pm 0.01$ & $0.007 \pm 0.002$ & $0.1 \pm 0.1$ & $0.31 \pm 0.03$ \\
\hline Beech, RL & $0.16 \pm 0.04$ & $-0.02 \pm 0.06$ & $-0.017 \pm 0.009$ & $0.003 \pm 0.003$ & $0.0 \pm 0.1$ & $0.25 \pm 0.09$ \\
\hline Beech TW, TL & $0.14 \pm 0.05$ & $1.6 \pm 0.7$ & $-0.026 \pm 0.008$ & $0.001 \pm 0.003$ & $0.4 \pm 0.3$ & $0.4 \pm 0.1$ \\
\hline Beech TW, RL & $0.1 \pm 0.3$ & $1.5 \pm 0.3$ & $-0.03 \pm 0.01$ & $0.005 \pm 0.002$ & $0.2 \pm 0.4$ & $0.4 \pm 0.1$ \\
\hline Fir EW & $0.0 \pm 0.5$ & $3.4 \pm 0.8$ & $-0.038 \pm 0.009$ & $0.006 \pm 0.005$ & $-0.1 \pm 0.1$ & $0.4 \pm 0.2$ \\
\hline Fir LW & $0.6 \pm 0.2$ & $0 \pm 1$ & $-0.030 \pm 0.009$ & $0.011 \pm 0.005$ & $-0.1 \pm 0.1$ & $0.25 \pm 0.09$ \\
\hline Spruce EW & $0.3 \pm 0.2$ & $3.4 \pm 0.8$ & $-0.041 \pm 0.009$ & $0.003 \pm 0.005$ & $0.0 \pm 0.2$ & $0.30 \pm 0.03$ \\
\hline Spruce LW & $0.6 \pm 0.2$ & $1.5 \pm 0.8$ & $-0.035 \pm 0.008$ & $0.006 \pm 0.002$ & $-0.1 \pm 0.1$ & $0.40 \pm 0.07$ \\
\hline
\end{tabular}

purpose, the physical parameters obtained from fits to SAXS ( $2 \bar{R}$ and $a)$ and WAXS data $\left(d_{200}, d_{004}, L_{200}\right.$ and $\left.L_{004}\right)$ at different RHs below the fiber saturation point ("SAXS results and "WAXS results" sections) were plotted as a function of moisture content at each RH step (Figure S11 in the ESM), as determined with DVS ("Vapor sorption results" section). A straight line was fitted to the data points of each sample, and the resulting slopes, normalized by the predicted value at moisture content $0 \%$, are shown in Table 3 .

Based on the results in Table $3, d_{004}$ and $L_{004}$ correlated positively and $d_{200}$ negatively with moisture content in all samples. Also the interfibrillar distance $a$ showed a clear positive correlation with moisture content in all samples except the RL section of beech normal wood, at least after omitting the clearly deviating values obtained for the latewood sections of the softwoods at RH 15\% (Figure S11). In fact, the relative changes observed in this parameter with moisture content were larger than those in any other parameter. $L_{200}$ seemed to have a weak positive correlation with moisture content in the beech samples, whereas a negative value was obtained for most softwood samples. However, as already pointed out in "WAXS results" section, the coherence length $L_{200}$ in the softwoods rather increased throughout the RH cycle than followed the RH changes directly. The behavior of $2 \bar{R}$ was different from $L_{200}$, presenting a weak positive correlation with moisture content in most samples. The differences between the samples will be analysed more deeply in the following discussion.
Summary of moisture-related changes in the nanostructure of different woods

The nanoscale moisture behavior of wood was approached in this work by using X-ray scattering methods SAXS and WAXS, complemented by SANS. As the employed techniques are sensitive to slightly different length scales and constituents of the wood nanostructure, a comprehensive picture should be created by comparing the results to each other. This will be attempted in the following with the aid of a simplified, ideal model for the general wood structure (Fig. 9), based on recent literature (Alméras and Clair 2016; Kang et al. 2019; Salmén et al. 2012). In Fig. 9, the CMFs are depicted as wavy rods with occasional aggregation, separated by water-accessible polysaccharides (hemicelluloses) and less hydrophilic lignin domains.

When water bound to the hemicelluloses evaporates from the ideal, generalized secondary cell wall structure (Fig. 9), the water-swollen polysaccharide matrix shrinks strongly, pulling the CMFs closer to each other ( $a$ decreases) and causing disruptions of the crystalline order especially on the CMF surfaces $(2 \bar{R}$ and $L_{200}$ decrease, $d_{200}$ increases). The shrinking matrix also contracts the CMFs in their longitudinal direction ( $d_{004}$ decreases), causing either bending of the CMFs or an increase in their twisting $\left(L_{004}\right.$ decreases). Most of these changes are at least partly reversible, meaning that the original wet-state structure can be regained after drying by increasing the moisture content of the cell wall. This requires breaking of the existing links within the matrix and 


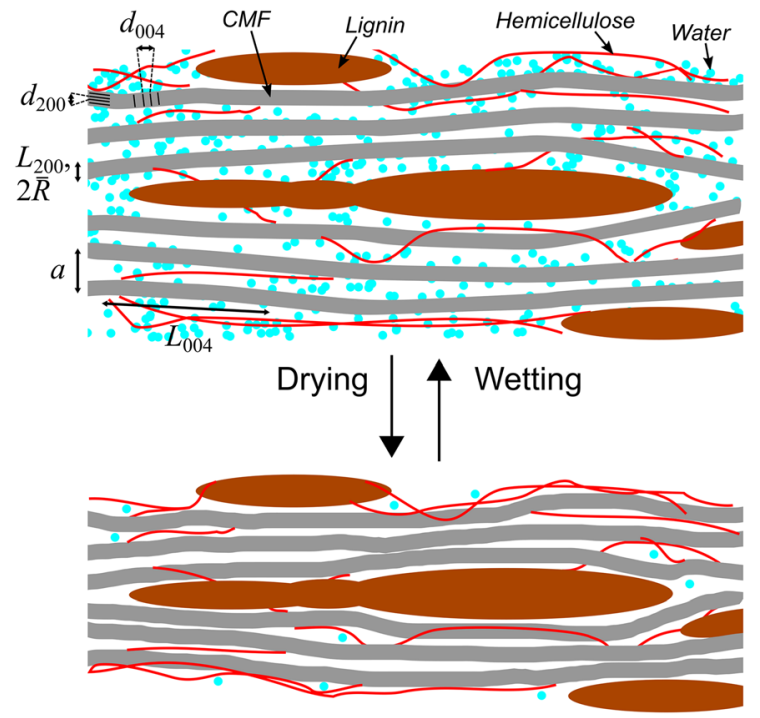

Fig. 9 Hypothetical sketch illustrating the effects of moisture changes on the wood nanostructure (proportions and dimensions of the components not in scale)

between the matrix and the CMFs, which enables further swelling of the structure to accommodate more water. When the rehydration is done with water vapor, a higher RH (vapor pressure) is required to reach the same moisture content, which is observed as hysteresis in the sorption isotherms. Even though almost full rehydration of wood may be reached by vacuum impregnation of liquid water (Thybring et al. 2017), our results (especially from DVS and SANS, "Vapor sorption results" and "SANS results" sections) show that not all nanostructural changes that took place during the initial drying of the wood samples were erased by immersing them back in liquid water at ambient conditions.

When looking into the differences between the samples, some important deviations from the idealized behavior outlined above can be found. Firstly, in line with previous observations on other hardwoods (Leppänen et al. 2011; Penttilä et al. 2019; Thomas et al. 2014), the interfibrillar distance $a$ in beech normal wood was smaller than in the softwood samples, and it was only slightly affected by moisture changes. Also the lateral width of the CMFs (parameters $2 \bar{R}$ and $L_{200}$ ) in beech normal wood changed less with moisture than in the other samples, suggesting a lower accessibility of the CMF surfaces to water in beech normal wood. These findings indicate that the
CMFs are more densely packed in normal hardwoods than in softwoods, making the CMFs and their bundles less sensitive to moisture changes. It can be speculated that the lower content of glucomannan in hardwoods could be connected with the observed differences, as it is the hemicellulose more directly associated with the CMFs in softwoods (Åkerholm and Salmén 2001).

Unlike the normal wood samples of beech, beech tension wood showed many similar trends with moisture changes as the softwood samples, including a strong correlation of the interfibrillar distance $a$ with moisture content and clear effects on the CMF diameter $\left(2 \bar{R}\right.$ and $\left.L_{200}\right)$. However, the numerical values of $a$ and $L_{200}$ were significantly larger in the tension wood samples than in any of the other samples. These results are in line with a longitudinally alternating structure for CMF bundles in the G-layer of tension wood, with pores of approximately $6 \mathrm{~nm}$ in diameter occasionally separating the fibrils (Clair et al. 2008; Sawada et al. 2018). Such diversity in the structure might also explain the seeming discrepancies between the data obtained for the tension wood samples in this study. In particular, the lateral coherence length $L_{200}$ measured by WAXS was roughly two times larger than the CMF diameter $2 \bar{R}$ determined with SAXS. This could be caused by a stronger contribution of larger crystallites formed by coalescence of neighboring CMFs to the WAXS intensities, whereas the thinner single sections of the CMFs would dominate the shoulder around $q=$ $0.2 \AA^{-1}$ in the SAXS intensities. The moisture-related changes observed in the tension wood nanostructure, on the other hand, are consistent with the proposed xero-gelation of the matrix and buckling of the CMFs taking place in a drying G-layer (Clair et al. 2006, 2008; Yamamoto et al. 2010). Our results showed a reversible decrease of the interfibrillar distance $a$ from above $6 \mathrm{~nm}$ at high moisture content to around $4 \mathrm{~nm}$ at low moisture content (Fig. 6), as well as an increased disorientation of the CMFs (wider azimuthal intensity distribution in "SAXS results" and "WAXS results" sections) at low moisture contents.

Lastly, the softwood samples behaved consistently with the idealized structure as described above in relation to Fig. 9, except for the lateral coherence length $L_{200}$ determined with WAXS. As can be seen from Fig. 8, the value of $L_{200}$ decreased first with 
drying from the never-dried state to RH $90 \%$, but then started to gradually increase almost independent of the RH. In most of the softwood samples measured after drying and rewetting, the value of $L_{200}$ was larger than in the original, never-dried state. This could possibly be an indication of a slow reorganization of cellulose chains on CMF surfaces, which could increase the size of well-ordered crystalline domains, similarly as speculated to happen during repeated drying and wetting treatments of other softwoods (Toba et al. 2013). Interestingly, an increase of the CMF width after the drying and rewetting cycle was also indicated by the WAXS ( $L_{200}$ in Fig. 8$)$ and SANS $(2 \bar{R}$ in Table 2) results for beech tension wood. Unlike in the softwood samples, however, these changes could probably be more reliably assigned to the coalescence of the CMFs, which is presumably common in the G-layer (Sawada et al. 2018).

One of the most interesting findings of the current study is the clear correlation of the longitudinal coherence length $L_{004}$ with the moisture content in all of the examined wood samples. In some earlier works, a "crystal length" of some tens of nanometers, as determined from the broadening of the 004 diffraction peak of cellulose, was thought to correspond to the length of crystalline segments in a CMF with alternating crystalline and amorphous domains along the fibril axis. According to the current understanding (Jarvis 2018), however, such extensive amorphous domains do not exist in the CMFs of native wood cell walls, even though disordered regions of a few glucose units with a much longer periodicity $(150 \mathrm{~nm})$ have been reported for ramie fibers (Nishiyama et al. 2003). Therefore, alternative explanations for the finite correlation length in the longitudinal direction of CMFs have been suggested, a chiral twist around the longitudinal axis and bending of the longitudinal axis probably being the strongest candidates (Fernandes et al. 2011; Jarvis 2018). Bending or buckling of CMFs has been proposed to take place during drying of the G-layer in tension wood (Clair et al. 2006) and it is possible that similar but weaker changes occur also in the lignified cell walls of normal woods. A similar mechanism was recently proposed to explain structural changes during drying also in primary cell walls (Huang et al. 2018), where the CMFs are thinner and the moisture content is considerably higher than in the secondary cell wall.
However, in case drying-induced bending of the CMFs would cause the observed decrease of $L_{004}$ at low moisture contents, one could expect the change to be considerably larger in tension wood than in any of the other samples. As the relative change of $L_{004}$ with moisture content was of similar magnitude in all samples (Table 3), an increase in the twisting with drying appears a more plausible explanation. Based on molecular dynamics simulations, the twist rate of CMFs and their bundles, and thereby also the longitudinal coherence length, can be affected for instance by the fibril dimensions (Kannam et al. 2017) or interactions with water (Paajanen et al. 2019). However, it is not clear if the systems simulated so far are sufficiently representative of the complex, multicomponent structure of the native wood cell wall.

\section{Conclusions}

Wood is highly sensitive to moisture changes, but their effects on the nanoscale structure of the wood cell wall are not clear. In this work, we correlated such changes with nanostructural parameters determined with X-ray and neutron scattering. Many of the measured parameters, such as the lateral packing distance between the CMFs and parameters describing their crystal structure, were found to follow the moisture changes. These correlations indicated a better crystalline order of cellulose in the presence of water than in the absence of it. However, from the differences exhibited by different types of wood, it is clear that the nanoscale effects of moisture depend somewhat on the wood species and the presence of reaction wood. These differences may be related to the detailed organization and chemical composition of structural elements in the wood cell wall, where particularly the matrix polymers seem to play an essential role. X-ray and neutron scattering have proved as excellent methods for studying moisture-related changes in wood nanostructure, enabling also detection of small, irreversible structural differences caused by the first drying of native wood.

Acknowledgments Open access funding provided by Aalto University. The ESRF (Experiment 02-01-885) and ILL (Experiment INTER-378) are thanked for providing beamtime. The SAXS and WAXS experiments were performed on the French CRG beamline D2AM at the ESRF. Pierre Lloria from the Partnership for Soft Condensed Matter 
(ESRF/PSCM) is acknowledged for helping with the humidity chamber. Emil Aaltonen Foundation (P.A.P.) and Academy of Finland (Grant Nos. 315768 (P.A.P.) and 309881 (L.R.)) are thanked for financial support. The WOS detector at D2AM was funded by the French National Research Agency (ANR) under the "Investissements d'avenir" program (Grant No. ANR-11EQPX-0010). This work benefited from the use of the SasView application, originally developed under NSF award DMR0520547. SasView contains code developed with funding from the European Union's Horizon 2020 research and innovation programme under the SINE2020 project (Grant No. 654000). We are grateful for the support by the FinnCERES Materials Bioeconomy Ecosystem.

Open Access This article is distributed under the terms of the Creative Commons Attribution 4.0 International License (http:// creativecommons.org/licenses/by/4.0/), which permits unrestricted use, distribution, and reproduction in any medium, provided you give appropriate credit to the original author(s) and the source, provide a link to the Creative Commons license, and indicate if changes were made.

\section{References}

Abe K, Yamamoto H (2005) Mechanical interaction between cellulose microfibril and matrix substance in wood cell wall determined by X-ray diffraction. J Wood Sci 51:334-338. https://doi.org/10.1007/s10086-004-0667-6

Agarwal UP (2014) $1064 \mathrm{~nm}$ FT-Raman spectroscopy for investigations of plant cell walls and other biomass materials. Front Plant Sci. https://doi.org/10.3389/fpls.2014. 00490

Åkerholm M, Salmén L (2001) Interactions between wood polymers studied by dynamic FT-IR spectroscopy. Polymer 42:963-969. https://doi.org/10.1016/S00323861(00)00434-1

Alméras T, Clair B (2016) Critical review on the mechanisms of maturation stress generation in trees. J R Soc Interface 13:20160550. https://doi.org/10.1098/rsif.2016.0550

Andersson S, Wikberg H, Pesonen E, Maunu SL, Serimaa R (2004) Studies of crystallinity of Scots pine and Norway spruce cellulose. Trees 18:346-353. https://doi.org/10. 1007/s00468-003-0312-9

Clair B, Alméras T, Yamamoto H, Okuyama T, Sugiyama J (2006) Mechanical behavior of cellulose microfibrils in tension wood, in relation with maturation stress generation. Biophys J 91:1128-1135. https://doi.org/10.1529/ biophysj.105.078485

Clair B, Gril J, Renzo FD, Yamamoto H, Quignard F (2008) Characterization of a gel in the cell wall to elucidate the paradoxical shrinkage of tension wood. Biomacromolecules 9:494-498. https://doi.org/10.1021/bm700987q

Dinwoodie JM (2000) Timber: its nature and behaviour, 2nd edn. E \& FN Spon, New York

Donaldson L (2008) Microfibril angle: measurement, variation and relationships-a review. IAWA J 29:345-386. https:// doi.org/10.1163/22941932-90000192
Doucet M, Cho JH, Alina G, Bakker J, Bouwman W, Butler P, Campbell K, Gonzales M, Heenan R, Jackson A, Juhas P, King S, Kienzle P, Krzywon J, Markvardsen A, Nielsen T, O’Driscoll L, Potrzebowski W, Ferraz Leal R, Richter T, Rozycko P, Snow T, Washington A (2018) SasView version 4.2. https://doi.org/10.5281/zenodo.1412041

Engelund ET, Thygesen LG, Svensson S, Hill CAS (2013) A critical discussion of the physics of wood-water interactions. Wood Sci Technol 47:141-161. https://doi.org/10. 1007/s00226-012-0514-7

Fang L, Catchmark JM (2014) Structure characterization of native cellulose during dehydration and rehydration. Cellulose 21:3951-3963. https://doi.org/10.1007/s10570-0140435-8

Fernandes AN, Thomas LH, Altaner CM, Callow P, Forsyth VT, Apperley DC, Kennedy CJ, Jarvis MC (2011) Nanostructure of cellulose microfibrils in spruce wood. Proc Natl Acad Sci USA 108:E1195-E1203. https://doi.org/10.1073/ pnas. 1108942108

Glass SV, Zelinka SL (2010) Wood handbook: wood as an engineering material: chapter 4. Centennial ed. General technical report FPL; GTR-190, U.S. Dept. of Agriculture, Forest Service, Forest Products Laboratory, chap Moisture relations and physical properties of wood, pp 4.1-4.19

Hashimoto T, Kawamura T, Harada M, Tanaka H (1994) Smallangle scattering from hexagonally packed cylindrical particles with paracrystalline distortion. Macromolecules 27:3063-3072. https://doi.org/10.1021/ma00089a025

Hill CAS, Ramsay J, Gardiner B (2015) Variability in water vapour sorption isotherm in Japanese Larch (Larix kaempferi Lamb.) —earlywood and latewood influences. Int Wood Prod J 6:53-59. https://doi.org/10.1179/ 2042645314Y.0000000090

Huang S, Makarem M, Kiemle SN, Zheng Y, He X, Ye D, Gomez EW, Gomez ED, Cosgrove DJ, Kim SH (2018) Dehydration-induced physical strains of cellulose microfibrils in plant cell walls. Carbohydr Polym 197:337-348. https://doi.org/10.1016/j.carbpol.2018.05. 091

Jakob H, Fratzl P, Tschegg S (1994) Size and arrangement of elementary cellulose fibrils in wood cells: a small-angle X-ray scattering study of Picea abies. J Struct Biol 113:13-22. https://doi.org/10.1006/jsbi.1994.1028

Jakob HF, Tschegg SE, Fratzl P (1996) Hydration dependence of the wood-cell wall structure in Picea abies. A smallangle X-ray scattering study. Macromolecules 29:8435-8440. https://doi.org/10.1021/ma9605661

Jarvis MC (2018) Structure of native cellulose microfibrils, the starting point for nanocellulose manufacture. Philos Trans R Soc A 376:20170045. https://doi.org/10.1098/rsta.2017. 0045

Jiang F, Li T, Li Y, Zhang Y, Gong A, Dai J, Hitz E, Luo W, Hu L (2018) Wood-based nanotechnologies toward sustainability. Adv Mater 30:1703453. https://doi.org/10.1002/ adma.201703453

Kang X, Kirui A, Dickwella Widanage MC, Mentink-Vigier F, Cosgrove DJ, Wang T (2019) Lignin-polysaccharide interactions in plant secondary cell walls revealed by solidstate NMR. Nat Commun. https://doi.org/10.1038/s41467018-08252-0 
Kannam SK, Oehme DP, Doblin MS, Gidley MJ, Bacic A, Downton MT (2017) Hydrogen bonds and twist in cellulose microfibrils. Carbohydr Polym 175:433-439. https:// doi.org/10.1016/j.carbpol.2017.07.083

Leppänen K, Bjurhager I, Peura M, Kallonen A, Suuronen JP, Penttilä P, Love J, Fagerstedt K, Serimaa R (2011) X-ray scattering and microtomography study on the structural changes of never-dried silver birch, European aspen and hybrid aspen during drying. Holzforschung 65:865-873. https://doi.org/10.1515/HF.2011.108

Lichtenegger H, Reiterer A, Stanzl-Tschegg SE, Fratzl P (1999) Variation of cellulose microfibril angles in softwoods and hardwoods-a possible strategy of mechanical optimization. J Struct Biol 128:257-269. https://doi.org/10.1006/ jsbi.1999.4194

Martínez-Sanz M, Gidley MJ, Gilbert EP (2015) Application of $\mathrm{X}$-ray and neutron small angle scattering techniques to study the hierarchical structure of plant cell walls: a review. Carbohydr Polym 125:120-134. https://doi.org/10.1016/j. carbpol.2015.02.010

Müller M, Burghammer M, Sugiyama J (2006) Direct investigation of the structural properties of tension wood cellulose microfibrils using microbeam X-ray fibre diffraction. Holzforschung 60:474-479. https://doi.org/10.1515/HF. 2006.078

Nishiyama Y, Langan P, Chanzy H (2002) Crystal structure and hydrogen-bonding system in cellulose $\mathrm{I} \beta$ from synchrotron $\mathrm{X}$-ray and neutron fiber diffraction. J Am Chem Soc 124:9074-9082. https://doi.org/10.1021/ja0257319

Nishiyama Y, Kim UJ, Kim DY, Katsumata KS, May RP, Langan P (2003) Periodic disorder along ramie cellulose microfibrils. Biomacromolecules 4:1013-1017. https://doi. org/10.1021/bm025772x

Nishiyama Y, Langan P, O’Neill H, Pingali SV, Harton S (2014) Structural coarsening of aspen wood by hydrothermal pretreatment monitored by small- and wide-angle scattering of X-rays and neutrons on oriented specimens. Cellulose 21:1015-1024. https://doi.org/10.1007/s10570-0130069-2

Paajanen A, Ceccherini S, Maloney T, Ketoja JA (2019) Chirality and bound water in the hierarchical cellulose structure. Cellulose. https://doi.org/10.1007/s10570-01902525-7

Penttilä PA, Kilpeläinen P, Tolonen L, Suuronen JP, Sixta H, Willför S, Serimaa R (2013) Effects of pressurized hot water extraction on the nanoscale structure of birch sawdust. Cellulose 20:2335-2347. https://doi.org/10.1007/ s10570-013-0001-9

Penttilä PA, Rautkari L, Österberg M, Schweins R (2019) Small-angle scattering model for efficient characterization of wood nanostructure and moisture behaviour. J Appl Crystallogr 52:369-377. https://doi.org/10.1107/ S1600576719002012

Plaza NZ, Pingali SV, Qian S, Heller WT, Jakes JE (2016) Informing the improvement of forest products durability using small angle neutron scattering. Cellulose 23:15931607. https://doi.org/10.1007/s10570-016-0933-y
Rongpipi S, Ye D, Gomez ED, Gomez EW (2019) Progress and opportunities in the characterization of cellulose-an important regulator of cell wall growth and mechanics. Front Plant Sci 9:1894. https://doi.org/10.3389/fpls.2018. 01894

Salmén L, Olsson AM, Stevanic J, Simonović J, Radotić K (2012) Structural organisation of the wood polymers in the wood fibre structure. BioResources 7:521-532

Sawada D, Kalluri UC, O’Neill H, Urban V, Langan P, Davison B, Pingali SV (2018) Tension wood structure and morphology conducive for better enzymatic digestion. Biotechnol Biofuels 11:44. https://doi.org/10.1186/ s13068-018-1043-x

Suzuki H, Kamiyama T (2004) Structure of cellulose microfibrils and the hydration effect in Cryptomeria japonica: a small-angle X-ray scattering study. J Wood Sci 50:351-357. https://doi.org/10.1007/s10086-003-0567-1

Svedström K, Lucenius J, Van den Bulcke J, Van Loo D, Immerzeel P, Suuronen JP, Brabant L, Van Acker J, Saranpää P, Fagerstedt K, Mellerowicz E, Serimaa R (2012) Hierarchical structure of juvenile hybrid aspen xylem revealed using X-ray scattering and microtomography. Trees 26:1793-1804. https://doi.org/10.1007/s00468-0120748-x

Thomas LH, Forsyth VT, Martel A, Grillo I, Altaner CM, Jarvis MC (2014) Structure and spacing of cellulose microfibrils in woody cell walls of dicots. Cellulose 21:3887-3895. https://doi.org/10.1007/s10570-014-0431-z

Thybring EE, Thygesen LG, Burgert I (2017) Hydroxyl accessibility in wood cell walls as affected by drying and rewetting procedures. Cellulose 24:2375-2384. https://doi. org/10.1007/s10570-017-1278-X

Toba K, Yamamoto H, Yoshida M (2013) Crystallization of cellulose microfibrils in wood cell wall by repeated dryand-wet treatment, using $\mathrm{X}$-ray diffraction technique. Cellulose 20:633-643. https://doi.org/10.1007/s10570012-9853-7

Vilkovská T, Klement I, Výbohová E (2018) The effect of tension wood on the selected physical properties and chemical composition of beech wood (Fagus sylvatica L.). Acta Fac Xylologiae Zvolen 60:31-40. https://doi.org/10. 17423/afx.2018.60.1.04

Yamamoto H, Ruelle J, Arakawa Y, Yoshida M, Clair B, Gril J (2010) Origin of the characteristic hygro-mechanical properties of the gelatinous layer in tension wood from Kunugi oak (Quercus acutissima). Wood Sci Technol 44:149-163. https://doi.org/10.1007/s00226-009-0262-5

Zabler S, Paris O, Burgert I, Fratzl P (2010) Moisture changes in the plant cell wall force cellulose crystallites to deform. J Struct Biol 171:133-141. https://doi.org/10.1016/j.jsb. 2010.04.013

Publisher's Note Springer Nature remains neutral with regard to jurisdictional claims in published maps and institutional affiliations. 